Posterior capsule opacification

\section{Risk factors for posterior capsule opacification}

S D Mcleod

\section{Resolving nebulous data}

mprovements in techniques, instrumentation, and intraocular lens design appear to have been associated with declining rates of posterior capsule opacification following cataract surgery. ${ }^{1}$ While morbidity associated with posterior capsule opacification and its treatment, Nd:YAG laser capsulotomy, is limited, progressive opacification affects quality of vision and visual function, while capsulotomy requires additional patient visits, consumes additional surgical resources, and introduces the potential risks of cystoid macular oedema and retinal detachment. Therefore, a better understanding of the mechanisms of posterior capsule opacification and its retardation would have obvious immediate benefits. Moreover, control of capsular optical and biomechanical characteristics following cataract extraction is essential if dynamic accommodative intraocular lenses, which change in optical conjugation power in response to ciliary body motion translated via the zonules and capsular bag, are to provide consistent and sustained performance.

In addition to providing further evidence suggesting an increased risk for posterior capsule opacity associated with specific features of intraocular lens design independent of material, the study presented by Mian and co-authors in this issue of the BJO (p 1453) supports the observation that we as yet do not have a complete understanding of all of the features that govern the behaviour of the capsular bag following cataract surgery; in this case, inability to exercise control over this process resulted in laser capsulotomy in up to $7.5 \%$ of cases at 24 months. Moreover, the comprehensive review provided by the authors draws attention to inconsistency in the literature with regard to its assessment of risk factors and strategies for the development of posterior capsule opacification after cataract surgery. This, in turn, obfuscates research directions for strategies to control the process of capsule opacification.

Well informed and sceptical readers will point out, as the authors acknowledge, that some previous studies, which have specifically addressed the issue of the relative risk for posterior capsule opacification associated with one piece acrylic compared with three piece acrylic intraocular lenses, have failed to demonstrate a significant difference in risk for posterior capsule opacity. ${ }^{2-4}$ As a previous study by Wallin and colleagues ${ }^{5}$ supports the authors' observations of an increased risk associated with the one piece design, one must consider explanations for these discrepancies, in so far as they may represent inconsistencies in study design or reporting.

One must first ask if a negative study that fails to identify a difference in outcomes is based upon the evaluation of relatively insensitive or unreliable parameters. This is a particular problem in the evaluation of posterior capsule opacification. Laser capsulotomy represents but a proxy for the process of opacification; it might be argued that it is a perfectly reasonable measure to study if our goal is to reduce the additional burden that the procedure places on patients and the medical system but, in the event that opacification which fails to meet criteria for treatment induces some compromise of visual function, there remains benefit to the reduction of these sub-interventional threshold levels of capsule opacity. Moreover, the goal of capsule control for reliable long term accommodative intraocular lens function requires an understanding of the mechanisms of posterior capsule fibrosis at an earlier stage than that associated with the need for laser intervention.

\section{The problem of posterior capsular opacification has not yet been con- quered}

Aslam and colleagues ${ }^{6}$ have presented, in the $B J O$, a systematic analysis of strategies to evaluate posterior capsule opacity and have pointed out that at present there is no entirely satisfactory method of comprehensively quantifying capsule opacity in vivo. In addition to regional quantitation of the optical density of capsule opacity, typically scored subjectively or by analysis of digitised photographs, capsule opacity has fibrotic and lens epithelial proliferative components that require three dimensional measurement. In order to assess the extent of opacification, researchers such as Sacu and colleagues have resorted to multiple modes of evaluation including a subjective score that ranks subtypes of fibrotic opacity, automated analysis of digitised photographs, and need for Nd:YAG laser capsulotomy. ${ }^{4}$ Hayashi and Hayashi ${ }^{7}$ have argued that multiple methods are indeed required to adequately describe these various features, and have suggested that retroillumination photography is helpful in describing the area of involvement, but Scheimpflug photography can further provide a measure of density. Aslam and colleagues have contended, however, that Scheimpflug imaging is hampered by its restriction to the examination of slit images and its analysis of back scattered rather than forward scattered light. Alternatively, this group has suggested an analysis system that attempts to analyse the three dimensional quality of capsular opacity ("texture $^{\prime \prime}$ ) through quantitation of measures of entropy in the intensity histogram of digitised retroilluminated photographic images. ${ }^{8}$ While these provide more direct measures than capsulotomy rates, the validity of their description of the complex patterns and varying degrees of capsule opacity have yet to be broadly confirmed.

Another explanation for inconsistent findings in studies of risks for capsule opacity would be that characteristics of the populations under study might vary significantly. For example, along with material properties and lens design, there is evidence that surgical technique, including factors such as the degree of capsulorhexis cover over the optic or cortical clean up might influence the course and pattern of subsequent capsule opacity. ${ }^{9}$ While Mian et al did not provide details of their management of the relation between the capsulorhexis edge and optic, or of cortical clean up, Smith and colleagues, ${ }^{10}$ in a study of the relation between capsule and lens edge overlap found that incomplete anterior capsule overlap, was associated with a significant increase in capsule opacity, and that this effect was indeed moderated by lens design. In order to compare studies and refine our protocols, these factors must be controlled as best we can.

Significant advances have been made in the design of intraocular lenses for implantation after cataract surgery, and a wide range of options are now available for patients and surgeons. However, the problem of posterior capsular opacification has not yet been conquered. It is to be hoped that more sophisticated methods of assessing and comparing the 
development of capsule opacity will help to guide research to this end.

Br J Ophthalmol 2005;89:1389-1390.

doi: $10.1136 /$ bjo.2005.074310

Correspondence to: Stephen D McLeod, MD, University of California San Francisco,

Department of Ophthalmology, and the Francis I Proctor Foundation, San Francisco, San Francisco, CA 94143, USA; mcleods@vision. ucsf.edu

\section{REFERENCES}

1 Apple DJ, Peng Q, Visessook, et al. Eradication of posterior capsule opacification. Documentation of a marked decrease in $\mathrm{Nd}$ :YAG laser posterior capsulotomy rates noted in an analysis of 5416 pseudophakic human eyes obtained post mortem. Ophthalmology 2001;108:18.

2 Bender L, Nimsgern C, Jose R, et al. Effect of 1piece and 3-piece AcrySof intraocular lenses on the development of posterior capsule opacification after cataract surgery. J Cataract Refract Surg 2004;30:786-9.

3 Nejima R, Miyata K, Honbou M. A prospective, randomised comparison of single and three piece acrylic foldable intraocular lenses. Br J Ophthalmo 2004;88:746-9.

4 Sacu S, Findl O, Menapace R, et al. Comparison of posterior capsule opacification between the 1-piece and 3-piece Acrysof intraocular lenses. Two year results of a randomized trial. Ophthalmology 2004;111:1840-6.

5 Wallin TR, Hinkley M, Nilson C, et al. A clinical comparison of single-piece and three piece truncated hydrophobic acrylic intraocular lenses. Am J Ophthalmol 2003;136:614-19.

6 Aslam TM, Dhillon B, Werghi N, et al. Systems of analysis of posterior capsule opacification. BrJ Ophthalmol 2002;86:1181-6.

7 Hayashi K, Hayashi H. Limitation of Scheimpflug videophotography system in quantifying posterior capsule opacification after intraocular lens implantation. Am J Ophthalmol 2004;138:696.

8 Aslam TM, Patton N, Graham J. A freely accessible, evidence based, objective system of analysis of posterior capsular opacification; evidence for its validity and reliability. $B M C$ Ophthalmol 2005;5:9.

9 Lane SS. Posterior capsule opacification and YAG capsulotomy. Am J Ophthalmol 2004;138:635-6.

10 Smith SR, Daynes T, Hinckley M, et al. The effect of lens edge design versus anterior capsule overlap on posterior capsule opacification. Am J Ophthalmol 2004;138:521-6.

\section{Tissue plasminogen activator therapy for the eye \\ R C Tripathi, B J Tripathi}

\section{Past, present, and future}

T he systemic (intravenous) administration of genetically modified (recombinant) tissue plasminogen activator (tPA) for thrombolysis in coronary arteries was approved by the US Federal Drug Administration in 1988. Since then, use of this approved drug has been extended to many nonapproved indications, especially in the eye. ${ }^{1}$

Tissue plasminogen activator is a naturally occurring serine protease produced by a variety of mammalian tissues, especially endothelial cells. Ocular tissues that contain tPA include the conjunctiva, cornea, trabecular meshwork, lens, vitreous, and retina. ${ }^{1-3}$ In normal adult human eyes, the aqueous humour contains a significant amount of tPA that is some 30 times more than in plasma. ${ }^{4}$ The major enzymatic action of tPA is the conversion of plasminogen (a zymogen) into plasmin, an active serine protease that hydrolyses fibrin. Compared to other fibrinolytic agents (for example, urokinase and streptokinase), tPA has several advantages: fibrin forms a ternary complex with tPA and plasminogen, which increases the rate of plasminogen activation several hundred-fold; in addition, tPA serves to protect plasmin from antiplasmin inhibitors until complete clot lysis is achieved. ${ }^{5-7}$ Even though cost effective, urokinase and streptokinase did not gain popularity because of their toxicity..$^{8-11}$
Since fibrin clots can occur in several sites of the body, including the eye, the notion was conceived that tPA therapy could be effective for the rapid dissolution of fibrin clots in the anterior chamber of the human eye, ${ }^{1412} 13$ as well as for lysis of fibrin clots after vitrectomy $y^{14-17}$ and failed blebs after glaucoma filtering surgery. ${ }^{18-20}$

As clinicians, we have to weigh the possible risks versus the benefits in deciding whether to pursue the prophylactic use of $\mathrm{APA}$

In this issue of the BJO (p 1458), Siatiri and colleagues report the results of a prospective, double masked randomised clinical trial in paediatric patients to evaluate the efficacy of $20 \mu \mathrm{g}$ tPA, administered intracamerally at the completion of congenital cataract surgery, with the aim of preventing severe fibrinous effusion and its sequelae. The rationale for this approach is based on the frequent occurrence of fibrin exudation in paediatric patients, which may cause complications including delayed visual recovery, after an otherwise successful cataract surgery. ${ }^{21} 22$ The randomisation in the study presumes that all patients would develop a fibrinous reaction after the surgical procedure, irrespective of tissue manipulation. The results show that compared to controls, the number of eyes that had anterior chamber reaction and fibrin formation was significantly reduced $(p=0.02$ to 0.01 ) on days $1,3,7$, and 14 after surgery and intracameral delivery of tPA. However, after 1-3 months of follow up, the difference between the two groups was statistically insignificant.

Prophylactic use of tPA is akin to the concept of using antibiotics preoperatively or intraoperatively to prevent postoperative infection of the eye. As clinicians, we have to weigh the possible risks versus the benefits in deciding whether to pursue such an approach. Because of the reactivity of ocular tissues and fibrinous exudation, especially in children, and in view of the fact that post-surgical intracameral administration of tPA in a child's eye requires general anaesthesia or short sedation, ${ }^{23} 24$ it may be reasonable to use tPA prophylactically. The half life of tPA in the blood circulation is short (about 5 minutes). ${ }^{725}$ However, it is possible that in the closed cavity of the anterior chamber of the eye, and with the low daily turnover of aqueous humour, tPA persists for several hours, ${ }^{1}$ which may justify intracameral delivery at the conclusion of surgery. We must also consider that paediatric patients who require surgical removal of congenital cataract often have many other ocular and systemic disorders and therefore warrant careful individual evaluation before administration of prophylactic tPA.

An amount of $25 \mu \mathrm{g}$ or more of tPA has been widely used intracamerally or intravitreally. ${ }^{13-16} 1926-29$ Based on extrapolation of the therapeutic serum concentration of tPA achieved with intravenous therapy for coronary thrombolysis, we advocated that $10 \mu \mathrm{g}$ would be an equivalent and safe dose for intracameral administration. ${ }^{1} \quad$ Several reports in the literature support the effectiveness of $10 \mu \mathrm{g}$ tPA for rapid (within minutes to a few hours) fibrinolysis in the anterior chamber and some investigators even recommend a dose as low as $3 \mu \mathrm{g} .{ }^{12030-35}$ Indeed, 
untoward side effects such as intraocular haemorrhage/rebleed/hyphaema, especially after surgical trauma, as well as corneal and retinal toxicity, have been reported with the use of $25 \mu \mathrm{g}$ or higher doses of tPA. ${ }^{13}{ }^{15-17} 263233$ 35-38 Although an optimal intracameral therapeutic or prophylactic dose of this very potent drug has not been determined, $10 \mu \mathrm{g}$ or less of TPA appears to achieve the desired fibrinolytic action in the anterior chamber with potentially minimal complications of rebleed and toxicity to the cornea and retina.

The topical application of tPA to dissolve fibrin clot in the anterior chamber has been advocated by several investigators, although studies in human eyes and experimental animal models have produced equivocal results. ${ }^{39-42}$ Because of the large molecular size $(68 \mathrm{kDa})$ of tPA, its penetration across the intact cornea may be limited. ${ }^{1}$ Transconjunctival or subconjunctival, sub-Tenon's capsule and trans-scleral routes deserve consideration, especially if clinicians prefer to initiate tPA therapy postoperatively after paediatric or adult cataract surgery. With this approach, the need for a short duration of general anaesthesia or sedation for intracameral injection especially in children, can be avoided and tPA could be administered in the postoperative follow up period on an as needed basis. This concept poses a challenge to clinicians and the pharmaceutical industry interested in developing novel methods for tPA drug delivery.

Br J Ophthalmol 2005;89:1390-1391. doi: 10.1136/bjo.2005.074401

\section{Authors' affiliations}

R C Tripathi, B J Tripathi, University of South Carolina School of Medicine, Columbia, SC, USA

Correspondence to: Professor Ramesh CTripathi, Department of Ophthalmology, Vision Research Laboratories, 6439 Garners Ferry Road, Columbia, SC 29209, USA; tripathi@med.sc.edu

\section{REFERENCES}

1 Tripathi RC, Tripathi BJ, Bornstein S, et al. Use of tissue plasminogen activator for rapid dissolution of fibrin and blood clots in the eye after surgery for glaucoma and cataract in humans. Drug Dev Res 1992;27:147-59

2 Park JK, Tripathi RC, Tripathi BJ, et al. Tissue plasminogen activator in the trabecular endothelium. Invest Ophthalmol Vis Sci 1987;28:1341-5.

3 Geanon JD, Tripathi BJ, Tripathi RC, et al. Tissue plasminogen activator in avascular tissues of the eye: a quantitative study of its activity in the cornea, lens, and aqueous and vitreous humors of dog, calf, and monkey. Exp Eye Res

1987:44:55-63.

4 Tripathi RC, Park JK, Tripathi BJ, et al. Tissue plasminogen activator in human aqueous humor and its possible therapeutic significance. Am J Ophthalmol 1988;106:719-22.

5 Kwaan HC, Samama MM, Nguyen G Fibrinolytic systems. In: Kwaan HC, Samama MM, eds. Clinical thrombosis. Boca Raton: CRC Press, 1989:23-31.

6 Weitz JI, Stewart RJ, Fredenburgh JC. Mechanism of action of plasminogen activators. Thromb Haemost 1999;82:974-82.

7 Collen D, Lijen HR. Tissue-type plasminogen activator: a historical perspective and personal account. J Thromb Haemost 2004;2:541-6.

8 Forrester JV, Williamson J. Lytic therapy in vitreous haemorrhage. Trans Ophthalmol Soc UK 1974;94:583-6.

9 Bramsen T. The effect of urokinase on central corneal thickness and vitreous haemorrahge. Acto Ophthalmol 1978;56:1006-12.

10 Textorius O, Stenkula S. Toxic ocular effects of two fibrinolytic drugs: an experimental electroretinographic study on albino rabbits. Arch Ophthalmol 1983;61:322-31.

11 Mindel JS. Special topics. Part 2: Drugs affecting blood. In: Duane TD, ed. Biomedical foundations of ophthalmology Philadelphia, Harper and Row, 1991:41:1-26.

12 Tripathi RC, Tripathi BJ, Park JK, et al. Intracameral tissue plasminogen activator for resolution of fibrin clots after glaucoma filtering procedures. Am J Ophthalmol 1991;111:247-28.

13 Snyder RW, Sherman MD, Allinson RW. Intracameral tissue plasminogen activator for treatment of excessive fibrin response after penetrating keratoplasty. Am J Ophthalmol 1990; 109:483-4.

14 Williams GA, Lambrou FH, Jaffe GJ, et al. Treatment of postvitrectomy fibrin formation with intraocular tissue plasminogen activator. Arch Ophthalmol 1988;106:1055-8

15 Jaffe GJ, Lewis H, Han DP, et al. Treatment of postvitrectomy fibrin pupillary block with tissue plasminogen activator. Am J Ophthalmol 1989;108:170-5

16 Jaffe GJ, Abrams GW, Williams GA, et al. Tissue plasminogen activator for postvitrectomy fibrin formation. Ophthalmology 1990;97: 184-9.

17 Dabbs CK, Aaberg TM, Aguilar HE, et al. Complications of tissue plasminogen activator therapy after vitrectomy for diabetes. Am J Ophthalmol 1990;1 10:354-60.

18 Ortiz JR, Walker SD, McManus PE, et al. Filtering bleb thrombolysis with tissue plasminogen activator. Am J Ophthalmol 1988;106:624-65.

19 Baker ND, Lehman DM, Weber PA, et al. Tissue plasminogen activator treatment of failing glaucoma filtering surgery. ARVO Abstract. Invest Ophthalmol Vis Sci 1991;32(suppl 4):1122.

20 Smith MF, Doyle JW. Use of tissue plasminogen activator to revive blebs following intraocular surgery. Arch Ophthalmol 2001;119:809-12.

21 Jameson NA, Good, WV, Hoyt CS. Inflammation after cataract surgery in children. Ophthalmic Surg Lasers 1992;23:99-102.

22 Fallaha N, Lambert SR. Pediatric cataracts. Ophthalmol Clin N Am 2001;14:479-92.

23 Klais CM, Hattenbach LO, Steinkamp GW, et al. Intraocular recombinant tissue-plasminogen activator fibrinolysis of fibrin formation after cataract surgery in children. J Cataract Refract Surg 1999;25:357-62.

24 Mehta JS, Adams GGW. Recombinant tissue plasminogen activator following paediatric cataract surgery. $\mathrm{Br} J$ Ophthalmol 2000;84:983-6.

25 Rijken DC, Otter M, Kuiper J, et al. Receptormediated endocytosis of tissue-type plasminogen activator (t-PA) by liver cells. Thromb Res Suppl 1990;10:63-71.

26 Wedrich A, Menapace R, Muhlbauer-Ries E. The use of recombinant tissue plasminogen activator for intracameral fibrinolysis following cataract surgery. Int Ophthalmol, 1994-95, 18:277-80.

27 Wedrich A, Menapace R, Reis E, et al. Intracameral tissue plasminogen activator to treat severe fibrinous effusion after cataract surgery. J Cataract Refract Surg 1997;23:873-7.

28 Georgiadis N, Bobiridis K, Halvatzis N, et al. Low-dose tissue plasminogen activator in the management of anterior chamber fibrin formation. J Cataract Refract Surg 2003;29:729-32.

29 Erol N, Ozer A, Topbas S, et al. Treatment of intracameral fibrinous membranes with tissue plasminogen activator. Ophthalmic Surg Lasers Imaging 2003;34:451-6.

30 Williams DF, Bennett SR, Abrams GW, et al. Lowdose intraocular tissue plasminogen activator for treatment of postvitrectomy fibrin formation Am J Ophthalmol 1990;109:606-7.

31 Abrams GW, Murray TG, Boldt HC, et al. Tissue plasminogen activator ( $t-P A)$ : determination of clinical limits of efficacy for intracameral delivery. ARVO abstract. Invest Ophthalmol Vis Sci 1991;32(suppl 4): 1226.

32 Starck T, Hopp L, Held KS, et al. Low-dose intraocular tissue plasminogen activator treatment for traumatic total hyphema, postcataract, and penetrating keratoplasty fibrinous membranes. $J$ Cataract Refract Surg 1995;21:219-24.

33 Lundy DC, Sidoti P, Winarko T, et al. Intracameral tissue plasminogen activator after glaucoma surgery. Indications, effectiveness, and complications. Ophthalmology 1996:103:274-82

34 Heiligenhaus A, Steinmetz B, Lapuente R, et al. Recombinant tissue plasminogen activator in cases with fibrin formation after cataract surgery: a prospective randomised multicentre study. Br J Ophthalmol 1998:82:810-15.

$35 \mathrm{Kim}$ MH, Koo TH, Sah WJ, et al. Treatment of total hyphema with relatively low-dose tissue plasminogen activator. Ophthalmic Surg Lasers 1998;29:762-6

36 Lambrou FH, Synder RW, Williams GA. Use of tissue plasminogen activator in experimental hypema. Arch Ophthalmol 1987; 105:995-7.

37 Wollensak G, Meyer JH, Loffler KU, et al. Bandlike keratopathy after treatment of postoperative fibrin reaction with tissue plasminogen activator. Klin Monatsbl Augenheilkd 1996;209:43-6.

38 Chen SN, Yang TC, Ho CL, et al. Retinal toxicity of intravitreal tissue plasminogen activator: case report and literature review. Ophthalmology 2003; 110:704-8.

39 Lim JI, Fiscella $\mathrm{R}$, Tessler $\mathrm{H}$, et al. Intraocular penetration of topical tissue plasminogen activator. Arch Ophthalmol 1991;109:714-17.

40 Lim Jl, Maguire AM, John G, et al. Intraocular tissue plasminogen activator concentrations after subconjunctival delivery. Ophthalmology 1993; 100:373-6.

41 Cellini M, Baldi A, Possati GL. Topical treatment of postvitrectomy fibrin formation with tissue plasminogen activator. Int Ophthalmol 1994-95; 18:351-3.

42 Zwaan J, Latimer WB. Topical tissue plasminogen activator appears ineffective for the clearance of intraocular fibrin. Ophthalmic Surg Lasers 1998;29:476-83. 


\section{Detecting ocular-visual function changes in diabetes}

\section{A Westall}

\section{It is essential for the chosen biomarkers to assess accurately ocular function as well as reproducible change}

n the 21 st century we are nearing the time when treatment of ocular disease is becoming a reality. As such, the ability to monitor disease progression and/or disease recovery is as important as the ability to detect disease related ocular change. Minimising measurement variability is intrinsic to monitoring accurately any chosen ocular-visual biomarker that best represents disease progression over time. This is the topic of the paper by Gilmore and co-workers

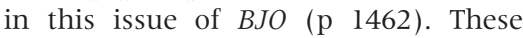
authors have described the measurement variability of the short wavelength (SW) automated perimetry (SWAP) in patients with diabetes. SWAP has been used primarily to detect vision loss and to monitor progressive visual field loss in glaucoma. ${ }^{1}$ SWAP is more sensitive in detecting glaucomatous changes than standard white on white (WW) perimetry. ${ }^{2}$ Gilmore and co-workers used the psychophysical frequency of seeing analysis as a measure of within examination variability, where the slope of the frequency of seeing curve represents threshold variability. Earlier Chauhan and co-workers ${ }^{3}$ integrated a psychophysical frequency of seeing paradigm into WW automated perimetry testing. They found that in patients with glaucoma and those with suspicion of glaucoma the variability in frequency of seeing was not necessarily explained by the response threshold or threshold deviation. Change in the slope of the frequency of seeing curve probably represents spontaneous change in threshold. Gilmore and colleagues find the higher estimate of within examination variability makes SWAP a less valuable biomarker in monitoring progression of certain ocular diseases. The increased sensitivity of SWAP has to be tempered with the higher within test variability of SWAP over standard WW perimetry.

Diabetic retinopathy is the single most common cause of blindness in the developed world. ${ }^{4}$ The prevalence of diabetes is increasing and potential blindness is threatening a rapidly growing number of working age individuals.
Currently, there is a one in 300-500 chance for a child developing type 1 diabetes by $18-20$ years of age..$^{5-7}$ of these, $98 \%$ will show evidence of retinal microvascular changes $15-20$ years after diagnosis. $^{8}$

Current treatments for diabetic retinopathy are based on the extent of the retinal vasculopathy. The progression of vascular abnormality involves change from background, to pre-proliferative, to proliferative disease over time. The Diabetic Retinopathy Study (DRS) ${ }^{9}$ and the Early Treatment in Diabetic Retinopathy Study (ETDRS) ${ }^{10}$ set the current standard of care. Treatment for proliferative retinopathy involves panretinal laser photocoagulation (PRP) used to ablate the peripheral retina and laser ablative therapy given when high risk proliferative retinopathy develops.

In the future, neuroprotective therapies might conceivably delay onset of proliferative retinal change in diabetes

But, what if the neuronal component of the retina is compromised along with, or even before, the earliest retinal microvascular complications become apparent? This is an area receiving increasing attention and is the focus of collaboration between the Hospital for Sick Children and St Michael's Hospital (Dr Shelley Boyd) in Toronto. Direct, non-invasive neuroretinal function testing of the human visual system demonstrates functional changes in the neuroretina of individuals with diabetes. Colour processing, in particular the processing of short wavelength stimulus, is abnormal in diabetes. ${ }^{11-13}$ Adults with type 1 diabetes show reduced blue-yellow colour vision discrimination before the onset of retinopathy. ${ }^{14}$ The deficit in the short wavelength pathway was the focus of the study by Gilmore and colleagues, who tested frequency of seeing (FOS) areas of known decreased SW sensitivity. The importance of this SW linked to the abnormal function of the SW cones. Yamamoto et al ${ }^{1516}$ demonstrated that the short wavelength (S) cones were compromised selectively in adults with type 1 diabetes. These changes were evident with or without evident retinal vasculopathy. A significant $(p<0.001)$ selective reduction in the amplitude of the short wavelength cone response suggests a defect at the level of the S-cone photoreceptor.

Our group and others have found deficits in the integrity of the SW or Scone pathway in patients with type 1 diabetes, with no evidence of retinopathy, using the colour visual evoked potentials (VEP). ${ }^{17}{ }^{18}$ The SW VEP latencies (time to respond to blue-yellow stimulus) of those with diabetes are delayed when compared with those without diabetes. ${ }^{17}$ We investigated the association between glucose control $\left(\mathrm{HbA}_{\mathrm{Ic}}\right)$ and colour vision in preteen $(<12.9$ years of age $)$ children with type 1 diabetes using the colour VEP. Glucose control was well controlled and did not affect the S-cone pathway in this young group of children with diabetes. However, pubertal status was associated significantly $(p=0.0114)$ and selectively with S-VEP latency: pubertal children with type 1 diabetes had delayed S-VEP latencies (mean S-VEP latency $=$ $144.3 \mathrm{~ms}$ ) when compared with the pre-pubertal children with type 1 diabetes (mean S-VEP latency $=$ $134.8 \mathrm{~ms}) .{ }^{18}$

An exciting development is the use of the multifocal electroretinogram (mfERG) to study multiple small regions of the retina individually. ${ }^{19-27}$ This enables precise mapping of the neural retina. Multifocal ERG studies of adults with diabetes demonstrate clearly local deficits of retinal function. ${ }^{19-27}$ Significant delays in the first order mfERG response, which is predominantly derived from bipolar cells, ${ }^{28}$ were found. ${ }^{20} 22$ Importantly, Han et $a l^{2021}$ found localised functional abnormalities that predicted the site of new vasculopathy (microaneurysms or leakage) observed 1 year later on clinical examination and confirmed by $50^{\circ}$ fundus photography.

Very recently, high frequency components of mfERG recordings have been found to resemble oscillatory potentials of the full field ERG. Wu and Sutter ${ }^{29}$ found that multifocal oscillatory potentials (mfOPs) were produced best by a flicker stimulus slowed by the insertion of dark stimulus frames. Bearse and colleagues $^{26}$ showed that the inner retinal mfOP response, derived from the slow flash mfERG recording, was abnormal in patients with diabetes. In addition response abnormalities were 


\section{EDITORIALS}

associated with the site of vascular leakage or haemorrhage.

Because diabetes is generally considered a disease of the retinal blood vessels current treatment paradigms are based on the extent of vascular damage and are typically given late in the disease, when significant end organ damage has already occurred. Perhaps the neuronal cells of the retina and visual pathways of the brain are damaged as well as retinal blood vessels in diabetes. In particular, our data show that abnormalities of the koniocellular pathway occur in adolescent children with diabetes in the absence of observable changes in the retinal vasculature. In the future, neuroprotective therapies might conceivably delay onset of proliferative retinal change in diabetes. In streptozotocin induced diabetic rats, neurons and glial cells in the inner plexiform and nuclear layers of the retina undergo apoptosis early in the course of diabetes ${ }^{30}$ and actually precede the development of microvascular lesions. $^{31}$

For studies investigating treatment paradigms it is essential for the chosen biomarkers to assess accurately ocular function as well as reproducible change. Gilmore and colleagues have set an excellent precedent in investigating variability in responses in paradigms already shown to be sensitive.

Br J Ophthalmol 2005;89:1392-1393.

doi: 10.1136/bjo.2005.073395

Correspondence to: Dr Carol A Westall, Ophthalmology and Vision Sciences, The University of Toronto and The Hospital for Sick Children, Department of Ophthalmology and Vision Sciences, Toronto, M5G 1X8, Canada; carol.westall@sickkids.ca

\section{REFERENCES}

1 Hutchings $\mathbf{N}$, Hosking SL, Wild JM, et al. Longterm fluctuation in short-wavelength automated perimetry in glaucoma suspects and glaucoma patients. Invest Ophthalmol Vis Sci 2001;42:2332-7.
2 Sample PA, Bosworth CF, Blumenthal EZ, et al. Visual function-specific perimetry for indirect comparison of different ganglion cell populations in glaucoma. Invest Ophthalmol Vis Sci 2000;41:1783-90.

3 Chauhan BC, Tompkins JD, LeBlanc RP, et al. Characteristics of frequency-of-seeing curves in normal subjects, patients with suspected glaucoma, and patients with glaucoma. Invest Ophthalmol Vis Sci 1993;34:3534-40.

4 Ewing FM, Deary IJ, McCrimmon RJ, et al. Effect of acute hypoglycemia on visual information processing in adults with type 1 diabetes mellitus. Physiol Behav 1998;64:653-60.

5 Daneman D. Risk of developing diabetes. Novo Nordisk Canada: www.novonordisk.ca, 2001.

6 Engelgau MM, Colagiuri S, Ramachandran A, et al. Prevention of type 2 diabetes: issues and strategies for identifying persons far interventions. Diabetes Technol Ther 2004:6:874-82.

7 Daneman D. In: Hux J, Booth G, Slaughter P, et al, eds. Diabetes in Ontario - an ICES practice atlas. Toronto: Institute for Clinical Evaluative Sciences, 2003:219-30.

8 Klein R, Klein BE, Moss SE, et al. The Wisconsin Epidemiologic Study of Diabetic Retinopathy. II. Prevalence and risk of diabetic retinopathy when age at diagnosis is less than 30 years. Arch Ophthalmol 1984;102:520-6.

9 Diabetic Retinopathy Study Report No 5. Photocoagulation treatment of proliferative diabetic retinopathy: relationship of adverse treatment effects to retinopathy severity. Dev Ophthalmol 1981;2:248-61.

10 Early Treatment Diabetic Retinopathy Study Research Group. Fundus photographic risk factors for progression of diabetic retinopathy. ETDRS report No 12. Ophthalmology 1991:98:823-33.

11 Bresnick GH, Condit RS, Palta $M$, et al. Association of hue discrimination loss and diabetic retinopathy. Arch Ophthalmol 1985; 103:1317-24.

12 Kurtenbach A, Flogel W, Erb C. Anomaloscope matches in patients with diabetes mellitus. Graefes Arch Clin Exp Ophthalmol 2002;240:79-84.

13 Ong GL, Ripley LG, Newsom RS, et al. Screening for sight-threatening diabetic retinopathy: comparison of fundus photography with automated color contrast threshold test. Am J Ophthalmol 2004;137:445-52.

14 Hardy KJ, Lipton J, Scase MO, et al. Detection of colour vision abnormalities in uncomplicated type 1 diabetic patients with angiographically normal retinas. $\mathrm{Br} J$ Ophthalmo 1992;76:461-4.

15 Yamamoto S, Kamiyama M, Nitta K, et al Selective reduction of the $\mathrm{S}$ cone electroretinogram in diabetes. $\mathrm{Br} J$ Ophthalmol 1996;80:973-5.

16 Yamamoto S, Takeuchi S, Kamiyama M. The short wavelength-sensitive cone electroretinogram in diabetes: relationship to systemic factors. Doc Ophthalmol 1997;94:193-200.

17 Crognale MA, Switkes E, Rabin J, et al. Application of the spatiochromatic visual evoked potential to detection of congenital and acquired color-vision deficiencies. J Opt Soc Am A Opt Image Sci Vis 1993;10:1818-25.

18 Elia YT, et al. Colour visual evoked potentials in children with type 1 diabetes: relationship to metabolic control. Invest Ophthalmol Vis Sci (in press).

19 Han Y, Bearse MA Jr, Schneck ME, et al. Towards optimal filtering of "standard" multifocal electroretinogram ( $m F E R G$ ) recordings: findings in normal and diabetic subjects. Br J Ophthalmol 2004;88:543-50.

20 Han Y, Bearse MA Jr, Schneck ME, et al. Multifocal electroretinogram delays predict sites of subsequent diabetic retinopathy. Invest Ophthalmol Vis Sci 2004;45:948-54.

21 Han Y, Bearse MA Jr, Schneck ME, et al Formulation and evaluation of a predictive model to identify the sites of future diabetic retinopathy. Invest Ophthalmol Vis Sci 2004;45:4106-12.

22 Fortune B, Schneck ME, Adams AJ. Multifocal electroretinogram delays reveal local retinal dysfunction in early diabetic retinopathy. Invest Ophthalmol Vis Sci 1999:40:2638-51.

23 Schneck ME, Bearse MA Jr, Han Y, et al. Comparison of mfERG waveform components and implicit time measurement techniques for detecting functional change in early diabetic eye disease. Doc Ophthalmol 2004;108:223-30.

24 Palmowski AM, Sutter EE, Bearse MA Jr, et al. Mapping of retinal function in diabetic retinopathy using the multifocal electroretinogram. Invest Ophthalmol Vis Sci 1997;38:2586-96.

25 Bearse MA Jr, Han Y, Schneck ME, et al. Retinal function in normal and diabetic eyes mapped with the slow flash multifocal electroretinogram. Invest Ophthalmol Vis Sci 2004:45:296-304.

26 Bearse MA Jr, Han Y, Schneck ME, et al. Local multifocal oscillatory potential abnormalities in diabetes and early diabetic retinopathy. Invest Ophthalmol Vis Sci 2004:45:3259-65.

27 Kurtenbach A, Langrova H, Zrenner E. Multifocal oscillatory potentials in type 1 diabetes without retinopathy. Invest Ophthalmol Vis Sci 2000;41:3234-41.

28 Hood DC, Frishman $\sqcup$, Saszik S, et al. Retina origins of the primate multifocal ERG: implications for the human response. Invest Ophthalmol Vis Sci 2002;43:1673-85.

29 Wu S, Sutter EE. A topographic study of oscillatory potentials in man. Vis Neurosci 1995; 12:1013-25.

30 Barber AJ, Lieth E, Khin SA, et al. Neural apoptosis in the retina during experimental and human diabetes. Early onset and effect of insulin. J Clin Invest 1998;102:783-91.

31 Rungger-Brandle E, Dosso AA, Leuenberger PM. Glial reactivity, an early feature of diabetic retinopathy. Invest Ophthalmol Vis Sci 2000;41:1971-80. 
Trypan blue

\section{Trypan blue staining of antiproliferative agents for trabeculectomy surgery and bleb needling}

\section{W Franks}

\section{Staining could be a useful tool in allowing comparison of the effects of different antiproliferative agents}

$\mathrm{H}$ ealey and Crowston, in the September issue of $B J O,{ }^{1}$ describe a novel and ingenious study using trypan blue to stain antiproliferative agents used during trabeculectomy surgery and trabeculectomy bleb needling. Trypan blue is commercially available as Vision Blue (Dorc, Zuidland, Netherlands). It is widely used in cataract surgery to stain the anterior capsule, and in vitreoretinal surgery to improve the visibility of preretinal membranes and is therefore readily available in most eye theatres.

They describe a clinical safety and efficacy trial backed up by laboratory based studies of colouring mitomycin $\mathrm{C}$ or 5-fluorouracil with the vital dye trypan blue $0.1 \%$. Addition of trypan blue in vitro had no effect on cell death rates in controls or on mitomycin $\mathrm{C}$ and 5-fluorouracil treated cells. In vivo, there was no difference in outcome in a series of eyes undergoing trabeculectomy surgery with trypan blue stained antiproliferative agent compared to controls. This technique has the potential to be useful both in research to compare outcomes of surgery as well as in clinical practice by enhancing safety in the use of antiproliferative agents and improving surgical technique.

Trabeculectomy is the surgical procedure of choice in most countries for treatment of chronic open angle glaucoma. Since the first description in 1968 by Cairns $^{2}$ the operation has survived challenges from procedures such as laser trabeculoplasty, ${ }^{3}$ holmium laser sclerostomy, ${ }^{4}$ artificial drainage devices $^{5-7}$ and, more recently, deep sclerectomy $^{89}$ and viscocanalostomy. ${ }^{10}{ }^{11}$ Some of the latter remain as lesser weapons in the glaucoma surgery armamentarium but none has stood the test of time to take trabeculectomy's foremost place in the surgical management of glaucoma.

Trabeculectomy is the most effective treatment for glaucoma for reducing intraocular pressure and preventing visual field loss, ${ }^{12-15}$ but relatively few cases come to surgery because of fear of complications. Eye drops are the first line treatment of chronic open angle glaucoma and the number of different types available leads to a myriad of possible combinations. The popularity and variety of medical treatments were greatly increased by the introduction of prostaglandin agonist eye drops in the mid 1990s and have been associated with a halving of trabeculectomy cases, ${ }^{16}{ }^{17}$ although the number performed at Moorfields Eye Hospital now appears to have stabilised (fig 1).

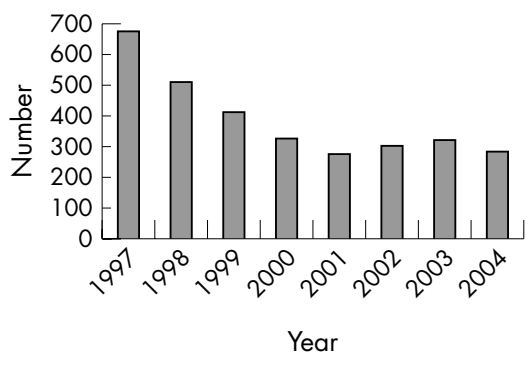

Figure 1 Number of trabeculectomy operations at Moorfields Eye Hospital 19972004.

The realisation that patients with progressive visual field loss need lower target pressures, ${ }^{18}$ and that this can be difficult to achieve even with multiple eye drops, means that trabeculectomy surgery will continue to be an important treatment to prevent blinding disease. In countries where the cost of drops is prohibitively expensive and the supply uncertain, trabeculectomy is the only feasible sight saving treatment.

The most important refinement to trabeculectomy surgery has been the use of antiproliferative agents to reduce postoperative subconjunctival fibrosis, prevent bleb failure, and achieve better intraocular pressure control. ${ }^{19} 20$ Evidence is accumulating that at lower intraocular pressures visual field progression is slowed or even arrested. ${ }^{21} 22$ In the pre-antiproliferative era an intraocular pressure of $21 \mathrm{~mm} \mathrm{Hg}$ or less was considered a successful outcome, whereas now intraocular pressures of $12 \mathrm{~mm} \mathrm{Hg}$ are being sought and achieved with surgery using the more potent antiproliferative agents. Over the past few years nearly all cases of trabeculectomy at Moorfields Eye Hospital have been with mitomycin $\mathrm{C}$ (fig 2).

It was soon recognised that the use of antiproliferative agents was associated with cystic bleb formation. ${ }^{23}$ Cystic blebs lead to an uncomfortable eye, late wound leaks, hypotony, and an increased risk of bleb related infections with potentially devastating consequences. ${ }^{24} 25$ If a small treatment area is used subconjunctival fibrosis occurs at the margins of the trabeculectomy bleb, confining drainage of aqueous humour to the treated area. The pressure of aqueous humour in this confined subconjunctival space causes thinning of the overlying conjunctiva over time. This led to the idea that cystic bleb formation would be less likely if peroperative treatments with antiproliferative agents were applied over a wide area of the upper fornix. This results in a greater area for aqueous humour drainage and reduced local tissue pressure. This necessitated a change in surgical technique from limbal to fornix based conjunctival flaps. ${ }^{26}{ }^{27}$ The downside to this change has been early bleb leaks because the antiproliferative agent inhibits healing of the anterior edge of the conjunctival flap. Surgeons learning trabeculectomy surgery are doing fewer cases at a time when the technique has become more demanding. By staining the antiproliferative agent with trypan blue it is clear, firstly, if an adequate area has been treated and, secondly, any areas of inadvertent treatment are highlighted. If the conjunctival edge is contaminated this will be visible and give an indication if additional sutures are needed to prevent wound leaks.

Healey and Crowston found that by using sponges pre-soaked with dyed antiproliferative agent the treatment area was larger than when the antiproliferative agent was injected into dry pre-placed sponges. This means that surgeons will need to be careful to do a thorough dissection of the subconjunctival space before inserting sponges as squeezing in wet sponges may cause leakage. In particular, extra care will need to be taken to prevent inadvertent treatment of the conjunctival edge by the dampened sponges and this will be easier to see if the antiproliferative agent is stained with trypan blue.

Healey and Crowston also describe the use of dyed 5-fluorouracil when needling failing trabeculectomy blebs. 

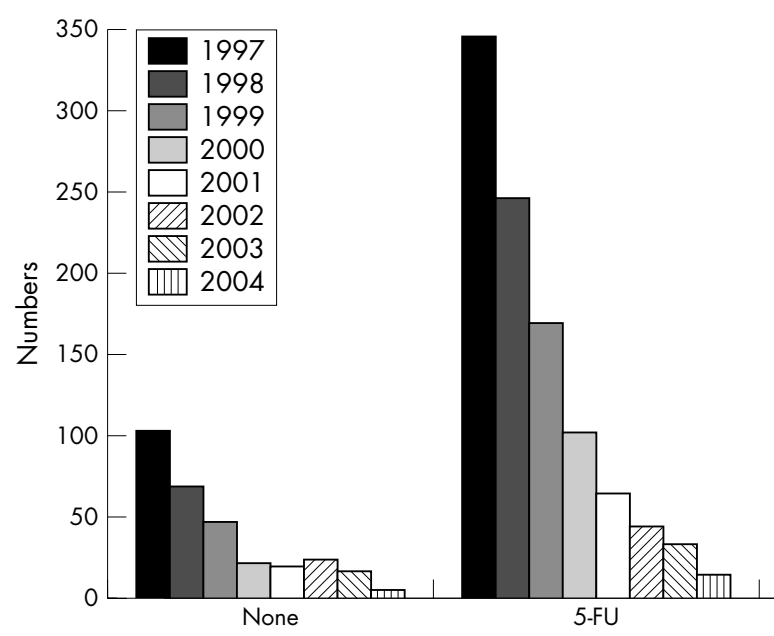

Figure 2 Trabeculectomy and antiproliferative agents 1997-2004. 5-FU, 5-fluorouracil, MMC, mitomycin C.

Trypan blue staining can show both the extent of the treatment area as the antiproliferative agent is injected into the subconjunctival space and, very importantly, can make penetration of the antiproliferative agent into the anterior chamber via the sclerostomy visible. It will make leakage back through the injection site into the tear film more obvious and demonstrate whether there is a risk of 5-fluorouracil induced keratopathy.

Comparing surgical outcomes between centres in trials of new surgical techniques in trabeculectomy surgery is problematic. Intraocular pressure lowering and visual field stability are insufficient alone to assess success. The comfort and appearance of the trabeculectomy bleb are also important outcomes for the patient. Clarke et al have published a useful guide to bleb appearances to aid researchers in quantifying morphological outcomes of trabeculectomy surgical technique. ${ }^{28}$

The surgeon chooses the concentration of mitomycin $\mathrm{C}$ but the area treated is variable. Dyeing antiproliferative agents with trypan blue may aid in standardising treatment areas. This makes comparing outcomes of treating series of patients difficult as the area and therefore the dosage of antiproliferative agent are not standardised. Staining could be a useful tool in the future in developing protocols allowing comparison of the effects of treating standardised areas of different antiproliferative agents.

Trabeculectomy is likely to remain the most commonly performed surgical operation for glaucoma for many years to come. However, concern remains about potential complications. Healey and Crowston's work will be of interest to clinicians as it promises to make surgery more predictable and to help in teaching safe surgical technique. It also promises to be of use in developing research protocols.

Some caution is necessary however. Trypan blue is not yet licensed for this application and, as the authors point out, further in vitro studies of fibroblast contraction may be needed before such approval is given.

Br J Ophthalmol 2005;89:1394-1395. doi: 10.1136/bjo.2005.076075

Correspondence to: Wendy Franks, Glaucoma Service, Moorfields Eye Hospital, City Road, London ECIV 2PD, UK; wendy.franks@ moorfields.nhs.uk

\section{REFERENCES}

1 Healey PR, Crowston JG. Trypan blue identifies antimetabolite treatment area in trabeculectomy. Br J Ophthalmol 2005;89:1152-6.

2 Cairns J. Trabeculectomy. Preliminary report of a new method. Am J Ophthalmol 1968;66:673-9.

3 Wise JB, Witter SL. Argon laser therapy for openangle glaucoma. A pilot study. Arch Ophthalmol, 1979, 1997;2:319-22

4 Hoskins HD Jr, Iwach AG, Vassiliadis A, et al. Subconjunctival THC:YAG laser thermal sclerostomy. Ophthalmology 1991;98:1394-9. glaucoma. Clinical trial. Br J Ophthalmol 1969;53:606-15.

6 Coleman AL, Hill R, Wilson MR, et al. Initial clinical experience with the Ahmed glaucoma Valve implant. Am J Ophthalmol 1995; 120:23-31.

7 Lloyd MA, Baerveldt G, Hever DK, et al. Initial complicated glaucomas. Ophthalmology surgery-deep sclerectomy. Vestn Oftalmol 1982;4:6-10.
5 Molteno AC. New implant for drainage in clinical experience with the Baerveldt implant in 1994; 101:640-50.

8 Federov SN, loffe DI, Ronkina TE. Glaucoma
9 Sanchez E, Schnyder CC, Sickenberg M, et al. Deep sclerectomy: results with and without collagen implant. Int Ophthalmol 1996-97;20:157-62.

10 Stegmann R, Pienar A, Miller D. Viscocanalostomy for open-angle glaucoma in black African patients. J Cataract Refract Surg 1999;25:316-22.

11 Carassa RG, Bettin P, Fiori M, et al. Viscocanalostomy versus trabeculectomy in white adults affected by open-angle glaucoma: a 2 year randomised, controlled trial. Ophthalmology 2003; 1 10:882-7.

12 Jay JL, Murray SB. Early trabeculectomy versus conventional management in primary open angle glaucoma. Br J Ophthalmol 1988;72:881-9.

13 Migdal C, Gregory W, Hitchings R. Long-term functional outcome after early surgery compared with laser and medicine in open-angle glaucoma. Ophthalmology 1994;101:1651-6.

14 Migdal C, Hitchings R. Control of chronic simple glaucoma with primary medical, surgical and laser treatment. Trans Ophthalmol Soc UK 1986; 105(Pt 6):653-6.

15 Leske MC, Heiil A, Hussein M, et al. Factors for glaucoma progression and the effect of treatment: the early manifest glaucoma trial. Arch Ophthalmol 2003;121:48-56.

16 Bateman DN, Clark R, Azuara-Blanco A, et al. The effect of new topical treatments on management of glaucoma in Scotland: an examination of ophthalmological health care. Br J Ophthalmol 2002;86:551-4.

17 Paikal D, Yu F, Coleman AL. Trends in glaucoma surgery incidence and reimbursement for physician services in the Medicare population from 1995 to 1998. Ophthalmology 2002;109:1372-6.

18 Jampel HD. Target pressure in glaucoma therapy. Acta Ophthalmol Scand Supp 1997;224:43-4.

19 Parrish RK 2nd, Schiffman JC, Feuer WJ, et al. The Fluorouracil Filtering Surgery Study Group. Prognosis and risk factors for early postoperative wound leaks after trabeculectomy with and without 5-fluorouracil. Am J Ophthalmol $2001 ; 132: 633-40$

20 Chen CW, Huang HT, Blair JS, et al. Trabeculectomy with simultaneous topical application of mitomycin-C in refractory glaucoma. J Ocular Pharmacol 1990;6:175-82.

21 AGIS Investigators. The relationship between control of intraocular pressure and visual field deterioration. Am J Ophthalmol 2000;130:429-40.

22 Khaw PT. The More Flow (Moorfields/MRC UK Study): a randomised prospective trial of intraoperative 5-fluorouracil versus placebo. Effect on long term pressure control and glaucoma progression. Am Acad Ophthalmol 2004:Abstract PAO 14

23 Franks WA, Hitchings RA. Complications of 5fluorouracil after trabeculectomy. Eye 1991;5(Pt 04):385-9.

24 Higginbotham EJ, Stevens RK, Musch DC, et al. Bleb-related endophthalmitis after trabeculectomy with mitomycin C. Ophthalmology 1996;103:650-6.

25 Edmunds B, Thompson JR, Salmon JF, et al. The National Survey of Trabeculectomy. III. Early and late complications. Eye 2002; 16:297-303

26 Rai PA, Bunce C, BartonK. Fornix versus limbus based conjunctival flap trabeculectomy and the incidence of bleb-related infection. Invest Ophthalmol Vis Sci 2003;44:E abstract.

27 Wells AP, Cordeiro MF, Bunce C, et al. Cystic bleb formation and related complications in limbus- versus fornix-based. conjunctival flaps in paediatric and young adult trabeculectomy with mitomycin C. Ophthalmology 2003;110:2192-7.

28 Clarke JC, Wells AP, Sangermani CD et al. A system for grading filtration blebs following trabeculectomy. Invest Ophthalmol Vis Sci 2003;44:E-Abstract, 1201. 